\title{
Fractomechanical Properties of As-Cast and Austempered SG Cast Iron Between $-40{ }^{\circ} \mathrm{C}$ and $+20{ }^{\circ} \mathrm{C}$
}

\author{
V.E. Fierro ${ }^{a / b} *$ J.A. Sikora ${ }^{c}$, F.R. Agüiera ${ }^{a / b}$, H.N. Alvarez Villar $^{a / b}$, \\ A.F. Ansaldi ${ }^{a}$, P.J.J. Ratto ${ }^{a}$ \\ ${ }^{a}$ CITEFA, Dto. Ciencia y Técnica de Materiales, Juan Bautista de Lasalle 4397 (1603), \\ Bs. As, Argentina. \\ ${ }^{b}$ Universidad de la Marina Mercante, UdeMM, Rivadavia 2258 (1034), Cap. Fed, Argentina. \\ 'INTEMA, Facultad de Ingeniería, Universidad Nacional de Mar del Plata, Av. Juan B. Justo \\ 4302 (7600), Mar del Plata, Bs. As, Argentina.
}

Received: August 28, 2001; Revised: April 30, 2002

\begin{abstract}
The spheroidal graphite (SG) cast iron fractomechanical response varies with the test temperature and with the microstructure parameters. In the present paper, we analyze this variation performing fractomechanical tests in a temperature range from $-40^{\circ} \mathrm{C}$ to $+20^{\circ} \mathrm{C}$, doing also Charpy and tensile tests for material characterization. The tests were carried out on as-cast samples and heat treated samples to obtain an ADI grade 1. In both cases, we studied samples taken from two well differentiated "Y" block sizes. The results obtained show that, for the chemical composition analyzed, both castings have a fractomechanical response decrease as the temperature diminishes. Besides, the block size enlargement produce a deterioration of the mechanical properties (the fracture toughness, mainly), for both castings.
\end{abstract}

Keywords: cast iron, ADI, fractomechanics, low temperature

\section{Introduction}

During the last years, the industrial use of SG cast irons has been increased and principally the use of ADI (Austempered Ductile Iron) due to the advantages they offer compared to cast steels and forged. Consequently, many investigations made to characterize and improve the mechanical properties of these materials have been developed. Nevertheless, there are some fields still unexplored. For example, the variation of the fractomechanical parameters as a function of the temperature test. Changes in the fractomechanical response at low temperature were studied for ferritic and pearlitic spheroidal cast iron ${ }^{1-4}$. There are very few works published on ADI about this ${ }^{5-7}$, and none of them analyze the influence of the solidification structure size.

In this work we study the fractomechanical response variation as a function of the temperature, in the low temperature range $\left(-40^{\circ} \mathrm{C}\right.$ to $\left.+20^{\circ} \mathrm{C}\right)$. Besides, we analyze the influence of changes in the solidification structure size.

\section{Experimental Procedure}

The chemical composition of the base melt is listed in Table 1. This basic composition allows to obtain all different unalloyed ADI grades. From this melt were cast, in green sand molds, "Y" blocks (ASTM A 536-84) of 13 and 75 $\mathrm{mm}$ in thickness. Specimens for fractomechanical tests were taken from the "Y" blocks according to ASTM E 1737-97. Also, unnotched Charpy specimens of $10 \times 10 \times 55 \mathrm{~mm}$ (ASTM A 327M-91) and tensile specimens of $6 \mathrm{~mm}$ in diameter (ASTM A 897M-90) were taken from the "Y" blocks.

Six sets of samples were taken randomly, each set containing half of the specimens from the $13 \mathrm{~mm}$ blocks and the other half from the $75 \mathrm{~mm}$ blocks. Each set was heat treated after machined excepting one set which was left as-cast. In this paper we include the results obtained with two sets, the one left as-cast and another one which qualifies as an ADI grade 1 and whose heat treatment is detailed in Table 2.

To characterize the material structure, the nodule count, nodule size and nodularity were determined (ASTM A 247- 
67, reap. 1990) on as-cast metallographic samples. The resulting values are listed in Table 3. Also the matrix type was determined, obtaining an ausferritic matrix in the ADI grade 1 case and a ferritic matrix with $5 \%$ of pearlite in the as-cast samples.

Tensile tests were made using a servohydraulic testing machine MTS 810 at different temperatures (Table 4). The procedure followed the ASTM E 8M-90a standard. The test temperature was controlled by means of an environmental chamber MTS 651, which uses a liquid nitrogen spray for

Table 1. Chemical composition of the SG cast iron (wt. \%).

\begin{tabular}{cccccccc}
\hline $\mathrm{C}$ & $\mathrm{Si}$ & $\mathrm{Mn}$ & $\mathrm{S}$ & $\mathrm{P}$ & $\mathrm{Mo}$ & $\mathrm{Cr}$ & $\mathrm{Ni}$ \\
\hline 3.1 & 3.4 & 0.53 & 0.01 & 0.03 & 0.01 & 0.05 & 0.05 \\
\hline
\end{tabular}

Table 2. Heat treatment.

\begin{tabular}{cccc}
\hline Code & Austenitizing & \multicolumn{2}{c}{ Austempering } \\
\hline & $\mathrm{T}\left[{ }^{\circ} \mathrm{C}\right]$ & $\mathrm{T}\left[{ }^{\circ} \mathrm{C}\right]$ & $\mathrm{t}[\mathrm{min}]$. \\
ADI 1 & 900 & 370 & 60 \\
\hline
\end{tabular}

Table 3. Microstructure characteristics.

\begin{tabular}{cccc}
\hline Code & $\begin{array}{c}\text { Nodule Count } \\
{\left[\mathrm{n} / \mathrm{mm}^{2}\right]}\end{array}$ & $\begin{array}{c}\text { Nodule } \\
\text { Size }\end{array}$ & $\begin{array}{c}\text { Nodularity } \\
{[\%]}\end{array}$ \\
\hline ACS & 221 & 6 & $>80$ \\
ACB & 137 & 4 & $>80$ \\
\hline
\end{tabular}

cooling. The Charpy impact tests were made at room temperature using a Shimadzu impact machine with $300 \mathrm{~J}$ maximum energy capacity, on unnotched specimens (ASTM A 327M-91 and ASTM A 897M-90). The Rockwell hardness was also determined (Table 4).

The fractomechanical parameter $\mathbf{J}$ tests were made according to ASTM E 1737-97 standard using the MTS 810 machine and the environmental chamber for temperature control. We used three point geometry samples of dimensions: $31 \mathrm{~mm}$ wide, $11 \mathrm{~mm}$ thick, $140 \mathrm{~mm}$ large and mechanical notch of $12 \mathrm{~mm}$ deep. The tests were made according to the single sample technique and crack length measured by compliance, using a clip gauge of $5 \mathrm{~mm}$ of gauge length positioned over the mouth of the crack in the specimen. It was necessary to make a side groove in the ascast samples to avoid any trouble related to an irregular growing of the crack front, leaving an effective thickness of $10 \mathrm{~mm}$.

Once the tests were made the fracture surfaces of some chosen samples were studied using an environmental scanning electron microscope (ESEM).

\section{Results}

In Figs. 1 and 2 the tension results are plotted as a function of the test temperature. These properties are necessary for the J parameter determination but they are also interesting by themselves. The $0.2 \%$ offset yield strength measured in the as-cast samples shows almost no variation with the temperature (Fig. 1), meanwhile the tensile strength

Table 4. Mechanical properties (average values of four measurements). "Measurements at $20{ }^{\circ} \mathrm{C}$. The scattering around the mean values of tension and yield strength are less than 5\% for the as-cast samples and less than $10 \%$ for the ADI samples.

\begin{tabular}{|c|c|c|c|c|c|}
\hline Code & $\begin{array}{c}\text { Impact Energy* }^{*} \\
{[\mathrm{~J}]}\end{array}$ & $\begin{array}{c}\text { Temperature } \\
{\left[{ }^{\circ} \mathrm{C}\right]}\end{array}$ & $\begin{array}{c}0.2 \% \text { Yield Strength } \\
{[\mathrm{MPa}]}\end{array}$ & $\begin{array}{c}\text { Tensile Strength } \\
{[\mathrm{MPa}]}\end{array}$ & Rockwell Hardness" \\
\hline \multirow[t]{4}{*}{ ACS } & 130 & 20 & 393 & 500 & $\mathrm{H}_{\mathrm{RB}} 84$ \\
\hline & & 0 & 428 & 557 & \\
\hline & & -20 & 426 & 569 & \\
\hline & & -40 & 445 & 599 & \\
\hline \multirow[t]{4}{*}{$\mathrm{ACB}$} & 25 & 20 & 368 & 437 & $\mathrm{H}_{\mathrm{RB}} 86$ \\
\hline & & 0 & 392 & 505 & \\
\hline & & -20 & 400 & 510 & \\
\hline & & -40 & 416 & 521 & \\
\hline \multirow[t]{4}{*}{ Adi1S } & 126 & 20 & 732 & 966 & $\mathrm{H}_{\mathrm{RC}} 33$ \\
\hline & & 0 & 829 & 1095 & \\
\hline & & -20 & 802 & 1060 & \\
\hline & & -40 & 775 & 1062 & \\
\hline \multirow[t]{4}{*}{ Adi1B } & 64 & 20 & 865 & 1073 & $\mathrm{H}_{\mathrm{RC}} 36$ \\
\hline & & 0 & 821 & 1059 & \\
\hline & & -20 & 794 & 990 & \\
\hline & & -40 & 800 & 1021 & \\
\hline
\end{tabular}




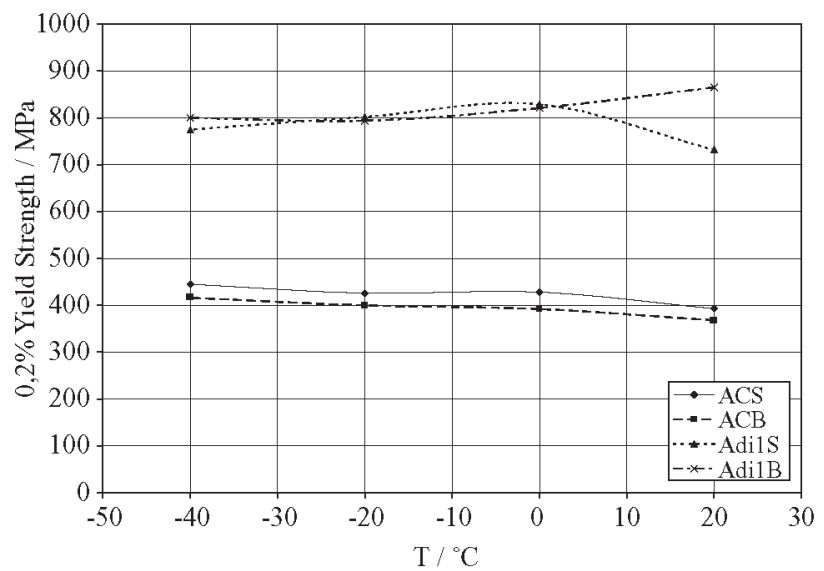

Figure 1. $0.2 \%$ offset yield strength vs. temperature.

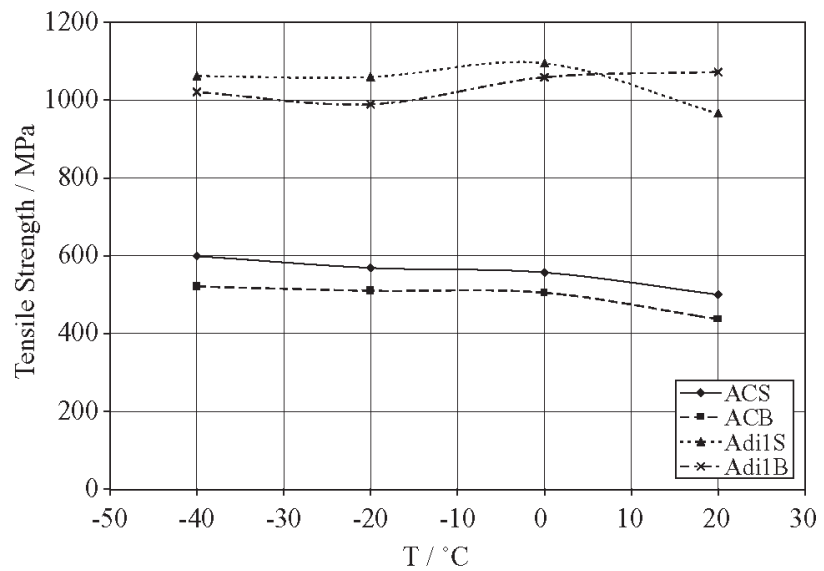

Figure 2. Tensile strength vs. temperature.

grows slowly as the temperature decreases (Fig. 2). For all cases, the as-cast samples taken from the small size "Y" blocks present slightly better properties than the ones taken from the bigger size blocks. In the small size block ADI samples case, the yield and tensile strength results show an increase and then a decrease as the test temperature diminishes $^{5}$. Instead, the big size block ADI samples only have a decrease of the yield and tensile strength results with the diminution of the temperature.

To compare the $\mathbf{J} v s$. temperature tests results, all values have been converted to the fractomechanical parameter $\mathrm{K}$, where $\mathrm{K}_{\mathrm{JC}}$ is the critical stress intensity factor based on $\mathrm{J}_{\mathrm{IC}}$, $\mathrm{K}_{\mathrm{JQ}}$ is the conditional critical stress intensity factor based on $\mathrm{J}_{\mathrm{Q}}$ and $\mathrm{K}_{\mathrm{Q}}$ is the conditional critical stress intensity factor. These results are described in Table 5 and Fig. 3.

The as-cast samples, taken from small size blocks, have an approximately constant $\mathrm{K}_{\mathrm{JC}}$ value of about $80 \mathrm{MPa} \cdot \mathrm{m}^{1 / 2}$ until $-20{ }^{\circ} \mathrm{C}$, and then an abrupt decrease until $-40{ }^{\circ} \mathrm{C}$. The ones taken from big size blocks present an important drop

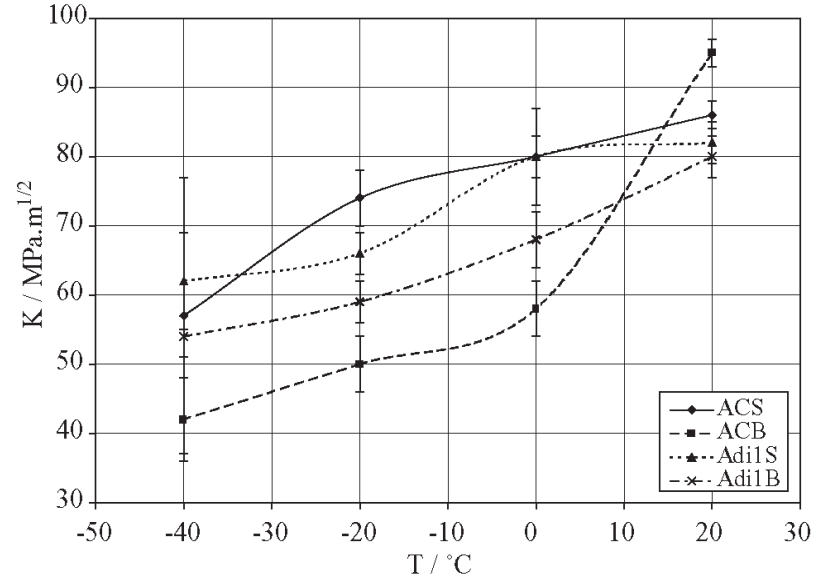

Figure 3. K values obtained as a function of the temperature.

Table 5. Fractomechanical parameter J test results, average values of three measurements. $* \mathrm{~K}_{\mathrm{JC}}, * * \mathrm{~K}_{\mathrm{JQ}}, * * * \mathrm{~K}_{\mathrm{Q}}$.

\begin{tabular}{lcc}
\hline Code & Temperature $\left[{ }^{\circ} \mathrm{C}\right]$ & $\mathrm{K}\left[\mathrm{Mpa} \cdot \mathrm{m}^{1 / 2}\right]$ \\
\hline ACS & 20 & $86 \pm 2^{*}$ \\
& 0 & $80 \pm 3^{*}$ \\
& -20 & $74 \pm 5^{*}$ \\
& -40 & $57 \pm 20^{* * *}$ \\
\hline ACB & 20 & $95 \pm 2^{*}$ \\
& 0 & $58 \pm 4^{*}$ \\
& -20 & $50 \pm 5^{* * *}$ \\
ADI1S & -40 & $42 \pm 6^{* * *}$ \\
& 20 & $82 \pm 3^{*}$ \\
& 0 & $80 \pm 7^{*}$ \\
ADI1B & -20 & $66 \pm 3^{*}$ \\
& -40 & $62 \pm 7^{* *}$ \\
& 20 & $80 \pm 3^{*}$ \\
& 0 & $68 \pm 4^{*}$ \\
& -20 & $59 \pm 4^{* *}$ \\
& -40 & $54 \pm 3^{* *}$ \\
\hline
\end{tabular}

over the whole measurement temperature range, going from a ductile to a brittle behaviour. The ADI samples also present a lowering in the fracture toughness values with the temperature decrease. Over the entire temperature range, the values measured with ADI samples taken from the $13 \mathrm{~mm}$ blocks are greater than the ones obtained with the $75 \mathrm{~mm}$ blocks. The lowering in the ADI samples values is less marked compared with the as-cast samples taken from big size blocks.

For the as-cast samples the fracture surfaces analysis showed a microvoids coalescence fracture mechanism at high temperatures, cleavage at low temperatures and a mix- 
ture of both mechanisms in the middle temperature range, for both solidification structure sizes.

The fracture mechanism found in the case of the ADI samples is a mixed type, with microvoids at the matrix near the nodules and cuasi-cleavage in the remaining internodular matrix zones. The rate between the microvoids area to the cuasi-cleavage area diminishes as the temperature decreases.

\section{Discussion}

The curves already shown present a ductile behaviour at the transition zone beginning, characterized by the $\mathrm{J}_{\text {IC }}{ }^{1}$ parameter, towards a more brittle behaviour characterized by the $\mathrm{K}_{\mathrm{IC}}$ parameter. There, the $\mathrm{J}_{\mathrm{IC}}$ values were converted to $\mathrm{K}_{\mathrm{JC}}$ values with the purpose of confront all values in a single graph. Then, it appears the problem about the existence of $\mathrm{K}_{\mathrm{Q}}$ or $\mathrm{K}_{\mathrm{JQ}}$ values in the curves transition zone. This problem is unavoidable, because at these temperatures the materials plasticity does not allow the $\mathrm{K}_{\mathrm{IC}}$ determination, at least for reasonably thick samples. Also, this plasticity is not enough to avoid the instability that appears in the case of low length stable crack growth, thus being impossible to obtain the complete J-R curve to determine a standard valid $\mathrm{J}_{\mathrm{IC}}$ value.

Comparing the as-cast samples taken from the 13 and the $75 \mathrm{~mm}$ blocks sizes, the fractomechanical parameters behaviour found can be explained by a transition curve displacement towards higher temperatures when the solidification structure size enlarges. Komatsu et al. ${ }^{2}$ have proved that in SG cast irons of ferritic-pearlitic matrix, the toughness was strongly modified just only for a pearlite content of over $50 \%$. Then, due to the low pearlite content of our samples, we can assume that they present a similar behaviour to the ferritic ones. In view of this similarity, if we consider the silicon content of our samples $(3,4 \%)$ and according to the Komatsu et al. data for ferritic samples, we can see that they predicted a transition temperature of $-50{ }^{\circ} \mathrm{C}$ in our case. This is compatible with the results obtained with the as-cast samples from the $13 \mathrm{~mm}$ blocks, but they still can not explain the $75 \mathrm{~mm}$ block results. Besides, Komatsu et al. ${ }^{3}$ measured the variation in toughness as a function of the solidification structure size for samples with $2,4 \%$ silicon content, having used samples cast in different molds to get the different structure sizes. They obtained a toughness increase near the upper shelf zone of $\mathrm{J}_{\mathrm{IC}}$ when the structure size enlarges, and also a transition temperature displacement towards higher temperatures when the structure size increases. Then, according to these results, we can explain the transition temperature shift observed in our as-cast 75 mm blocks samples and the fact that the toughness values measured in these samples exceeded the corresponding values of the $13 \mathrm{~mm}$ samples measured at room temperature.

The toughness measured in ADI 1 samples show a simi- lar behaviour, similar in shape and value, to Dorazil and Holzmann $^{5}$ data, in the case of non alloyed compositions with only $2,5 \%$ of silicon, austempering temperature of 400 ${ }^{\circ} \mathrm{C}$ during half an hour, low nodularity (60\%) and similar mechanical properties.

On the other hand, our measurements show a similar drop behaviour in shape but with values increased around $30 \%$ at room temperature and around $12 \%$ at $-40{ }^{\circ} \mathrm{C}$, compared to the Doong et al. ${ }^{6}$ data, in the case of samples with $2,3 \% \mathrm{Si}, 0,5 \% \mathrm{Cu}, 0,25 \% \mathrm{Mo}, 0,5 \% \mathrm{Ni}$, with austempering temperature of $350{ }^{\circ} \mathrm{C}$ during 5 hours and a nodularity of $88 \%$. This value disagreement could be due to the different composition and treatment, and also to the fact that the Doong et al. values are all $\mathrm{K}_{\mathrm{Q}}$, so slightly lower than $\mathrm{K}_{\mathrm{IC}}$ if there is plasticity.

There are no previous studies about the fracture toughness variation with temperature when the solidification structure size changes. We can state that this change seems to be a slightly values shift, towards higher temperatures, comparing the $13 \mathrm{~mm}$ block samples with the $75 \mathrm{~mm}$ block samples.

The fracture mechanisms that appeared in the fracture surfaces analysis are coincident with those reported in the bibliography ${ }^{2-3,5-8}$ and do not change with the modification in the solidification structure size.

\section{Conclusions}

We have characterized the fracture toughness behaviour at low temperatures for as-cast and austempered SG cast iron.

The correlation between the fracture toughness and the temperature was made by means of $\mathrm{K}$ equivalent, because the materials response at the upper toughness limit (upper shelf) is conservative. This procedure allows us to study a large temperature range.

The as-cast and austempered cast iron present a different fractomechanical response within the temperature range analyzed. However, these differences are slight for the studied composition. This slight difference found between the as-cast and the ADI toughness behaviour is due to the silicon content, which makes a transition temperature shift of the as-cast results leading to a values superposition in the range analyzed.

The change in solidification structure size between the 13 and $75 \mathrm{~mm}$ block sizes causes a mechanical properties deterioration, specially in the fracture toughness measurements. The fracture toughness deterioration is greater in the as-cast state compared to ADI. The austempering heat treatment diminishes the influence of the original solidification structure size of the samples on the fracture toughness.

The change in the solidification structure size do not introduce new fracture mechanisms. 


\section{Acknowledgments}

This work was supported by Agencia Nacional de Promoción Científica y Tecnológica, PICT 97/02156. The authors wish to thank the collaboration given by the INTEMA, the UdeMM Foundation and CITEFA's Prototype Department. We also thank C. Sommers, A. Reynoso and F. Agüera for their assistance.

\section{References}

1. Kobayashi, T. Advanced Materials Research, v. 4-5, p. 47-60, 1997.

2. Komatsu, S.; Shiota, T.; Nakamura, K.; Kyogoku, H. Advanced Materials Research, v. 4-5, p. 189-194, 1997.
3. Komatsu, S.; Shiota, T.; Matsuoka, T.; Nakamura, K. AFS Transactions, n. 105, p. 121-125, 1994.

4. Bradley, W.L.; Srinivasan, M.N. International Materials Reviews, v. 35, n. 3, p. 129-161, 1990.

5. Dorazil, E.; Holzmann, M. Proceedings of the World Conference on ADI, AFS, Bloomingdale, IL, USA, p. 32-66, 1991.

6. Doong, Ji-Liang.; Ju, Fu-Cheng. Chen, Hsing-Shih., Chen, Lien-Wen., Journal of Materials Science Letters, v. 5, p. 555-558, 1986.

7. Faucher, B.; Wang, K.C.; Gagné, M. AFS Transactions, n. 71, p. 127-132, 1987.

8. Putatunda, S.; Singh, I. Journal of Testing and Evaluation, v. 23, n. 5, p. 325-332, 1995. 